\title{
Socio-demographic characteristics and quality of life among women in the 3rd trimester of pregnancy living in Erzurum city center
}

Erzurum il merkezinde yaşayan üçüncü trimester gebelerin sosyodemografik özellikleri ve yaşam kaliteleri

Elif Oksan Calikoglua, (Dilal Betul Akcay, (D) Duygu Kavuncuoglu ${ }^{\mathrm{a}}$ (D) Esra Cinar Tanriverdi ${ }^{\mathrm{b}}$, (D)el Bilge Yerli $^{\mathrm{a}}$ (D) Sara Salcan ${ }^{\mathrm{c}}$

${ }^{a}$ Ataturk University, School of Medicine, Department of Public Health, Erzurum, Turkey

b Ataturk University, School of Medicine, Department of Medical Education, Erzurum, Turkey

${ }^{\mathrm{c}}$ Erzincan University, School of Medicine, Department of Public Health, Erzincan, Turkey

\begin{abstract}
Introduction: In this research, it is aimed to determine the relationship between quality of life and socio-demographic variables in the third trimester of pregnancy in Erzurum.

Methods: The study was conducted as a descriptive field survey between 1 December 2016 and 31 January 2017. The universe of the research is composed of 226 pregnant women in Erzurum city center. SPSS for data recording and analysis. Ver.22.0 package program is used. Descriptive statistics are presented as mean \pm standard deviation, percent and frequency distributions. The Mann Whitney-U test was used to assess the quality of life and $\mathrm{p}<0.05$ was considered statistically significant.

Results: All pregnant women in this study are at least 28 weeks in pregnancy. The mean age of the women participating in the survey is $28.2 \pm 5.8(18$ 44 ) and $4 \%$ of them are 19 years old or younger. Of pregnant women, 39.3\% were primary school graduates. Pregnant women's mean duration of marriage is $6.5 \pm 4.9$ years. Unintended pregnancy rate is $21.7 \%$. The mean number of pregnancies is $2.6 \pm 1.5$. Pregnant women who give birth by caesarean section rate is $27 \%$. Additionally, $15 \%$ of the pregnant have a chronic disease and 6.6 of them are smoker. According to SF-36 quality of life form scales; there was a significant difference between those who are educated on primary education, those who have regular income, those who are willingly pregnant in vitality, mental health, social functioning areas; spousal primary school education and the presence of social security in mental health, vitality and pain scores. In addition, scores of physical function, physical and emotional role, mental health and social functioning were significantly lower in smokers.
\end{abstract}

Conclusion: In our study it has been observed that the level of education affects many measures of quality of life. Regular income and social security have significantly affected the quality of life. In addition, a healthy pregnancy process is possible in women who have intended pregnancy.

Keywords: pregnancy, SF-36, third trimester, quality of life

\section{$\ddot{O} \mathbf{Z}$}

Giriş: $\mathrm{Bu}$ araştırmada Erzurum il merkezinde yaşayan 3. trimester gebelerin sosyodemografik özellikleri, yaşam kalitesi ve bunlar arasındaki ilişkisinin belirlenmesi amaçlandı.

Yöntem: Araştırma 1 Aralık 2016- 31 Ocak 2017 tarihleri arasında tanımlayıcı tipte saha araştırması şeklinde yapıldı. Araştırmanın evrenini Erzurum il merkezinde bulunan 226 gebe oluşturdu. Etik kurul ve araştırma izni alınan çalışmanın, veri kaydı ve analizi için SPSS. Ver.22.0 paket programı kullanıld. Tanımlayıc istatistikler ortalama, ortanca, standart sapma, yüzde ve frekans dağılımları olarak sunuldu. Yaşam kalitesi değerlendirilmesinde Mann Whitney-U testi kullanıld1, $\mathrm{p}<0,05$ istatistiksel olarak anlamlı kabul edildi.

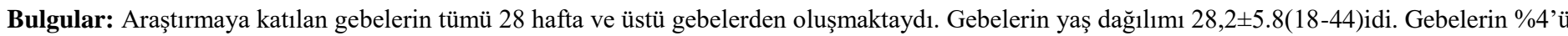

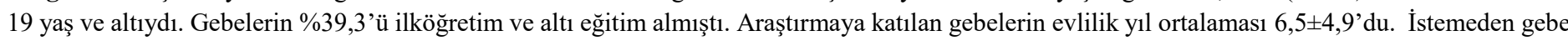
kalma oranı \%21,7 idi. Ortalama gebelik sayısı $2,6 \pm 1,5^{\prime}$ du. Sezeryan ile doğum yapan gebe oranı $\% 27$ 'ydi . Kronik hastalı̆ı olan gebe oranı $\% 15^{\prime}$ ti. Sigara içen gebe oranı\%6,6'ydı. SF-36 yaşam kalitesi formu ölçeklerine göre; ilköğretim üzeri eğitim alma, düzenli geliri olma ve isteyerek gebe kalma ile vitalite, ruhsal sağlık ve sosyal işlevsellik alanları; eşi ilköğretim üzeri eğitimli olma ve sosyal güvence varlığı ile ruhsal sağlık, vitalite ve ağrı alan puanları arasında anlamlı fark bulundu. Ayrıca sigara içen gebelerde fiziksel fonksiyon, fiziksel ve emosyonel rol güçlüğü, ruhsal sağlık ve sosyal işlevsellik alan puanları anlamlı düşük bulundu. 
Sonuç: Çalışmamızda eğitim düzeyinin yaşam kalitesinin pek çok ölçeğini etkilediği görülmüştür. Düzenli gelir ve sosyal güvence varlığı yaşam kalitesini önemli ölçüde etkilemiştir. Ayrıca sağlıklı bir gebelik süreci geçirebilmek isteyerek gebe kalan annelerde mümkündür.

Anahtar Kelimeler: gebelik, SF-36, üçüncü trimester, yaşam kalitesi

Submission: Jan 03, 2018

Acceptance: Mar 29, 2018

E-Mail: close2909@gmail.com

Correspondence: Hilal Betul Akcay, MD

Atatürk University, School of Medicine, Morphology building, Department of Public Health Yakutiye / Erzurum

www.fppc.com.tr

\section{Giriş}

Teknolojinin gelişmesiyle sağlık alanında hastalık tanı ve tedavisinde mesafeler kat edilmiş olması yaşam süresini uzatmış ve kronik hastalıklarla yaşama oranını arttırmıştır [1]. Sadece biyolojik hastalıkların tedavisi değil aynı zamanda psiko-sosyal sorunların giderilmesi yönünde çalışmaların artmasına sebep olmuştur.

Dünya Sağlık Örgütü(DSÖ)'nün 1948'de sağlığı sadece hastalığın ya da sakatlığın olmaması değil fiziksel, sosyal ve ruhsal olarak iyilik durumu şeklinde tanımlamış, sonrasında yaşam kalitesi konusu önem kazanmıştır [2]. Yaşam kalitesi subjektif yaşanan niteliktir tıp teknikleri, laboratuvar işlemleriyle ölçülemez. Kişilerin kendi fiziksel psikolojik ve sosyal işlevlerinden ne ölçüde memnun oldukları veya ne ölçüde rahatsız olduklarının saptanmasıdır [3]. Yaşam kalitesi çok yönlü ve sadece kişinin sağlık durumunu içermeyen aynı zamanda amaçlarını, standartlarını, umutlarını, beklentilerini de içeren geniş bir kavramdır [4]. DSÖ 1997'de yaşam kalitesini "kişinin kendi durumunu, kendi kültürü ve değerler sistemi içinde algılayış biçimi” olarak tanımlanmıştır. DSÖ’nün yaşam kalitesi kavramı içinde bağımsızlık düzeyi, ruh sağlığı, inançlar, çevresel etkenler, fiziksel sağlık da yer almaktadır [5].

Gebelik periyodu kadınların biyo-psiko-sosyal dengesinde, aile ve iş yerindeki rollerinde değişikliğe sebep olan doğal bir süreç olmakla beraber anne ve bebek arasında ebeveynlik ilişkisinin kurulduğu yaşamsal bir kriz dönemidir [6,7]. Gebelik esnasında fizyolojik ve psikolojik bütün değişiklikler annenin gebeliğe uyum sağlaması amacıyla meydana gelmektedir [8]. Gebeliğe uyum süreci her kadının geçmiş yaşam deneyimi, kültür düzeyi, ailedeki mutluluk derecesi, çevresindeki rol modeller, gebeliğinin planlı olup olmaması, gebelik ve doğum konusundaki bilgi düzeyiyle bağlantılıdır [7,9]. Ayrıca korku ve endişelerinin makul sınırlarda olması sahip olduğu ekonomik koşullar ailenin ve toplumun sosyal desteği gebelik sürecini ve bu süreçte görülen değişiklikleri kabullenmeyi etkiler [9].

Gebelikle birlikte artan fiziksel semptomlar yorgunluk, duygusal değişiklik ve sınırlılıklar yaşam kalitesinin birçok alanında azalmaya neden olduğu ifade edilmiştir [10]. Anne adayının yeteri kadar gebeliğe uyum sağlayamaması yaşam kalitesini olumsuz etkileyebilmektedir [11]. Son yıllarda özellikle kronik hastalıklarda yaşam kalitesinin değerlendirilmesine yönelik çalışmalar artmıştır. Ancak gebelikte yaşam kalitesi ile ilgili çalışmalar yetersizdir. Bu araştırmanın amacı Erzurum il merkezinde yaşayan 3. trimester gebelerin sosyo-demografik özellikleri ve yaşam kalitesini belirlemektir.

\section{Yöntem}

Araştırma tanımlayıcı ve kesitsel tipte olup veriler 1 Aralık 2016-31 Ocak 2017 tarihleri arasında toplamıştır. Araştırmanın evreni Erzurum il merkezinde yaşayan tüm gebeler olarak belirlenmiş, İl Sağlık Müdürlüğ̈’nden edinilen bilgilerle 2015 yılında il merkezi gebe sayısı 8474 olduğu tespit edilmiştir. Evreni bilinen örneklem yöntemiyle \%95 güven aralığında örneklem 226 kişi olarak hesaplanmıştır ve örneklemin tamamına ulaşılmıştır. Kadın doğum polikliniklerinde muayene için başvuran hastalara muayene öncesi, sözlü onam alınarak yüz yüze görüşme yöntemiyle yaklaşı 15 dakika süren anket formu uygulanmıştır.

Verilerin toplanmasında iki anket formu kullanılmış olup birinci form yaş eğitim düzeyi aile türü çalışan durumu ve doğurganlıkla ilgili sosyodemografik özellikleri sorgulayan soru formudur. İkinci form yaşam kalitesiyle ilgili SF-36 kısa formdur. SF-36 Yaşam Kalitesi Ölçeği: 1987 y1lında Amerika Birleşik Devletleri'nde klinik uygulama, araştırma, sağlık politikalarını ve genel populasyonu değerlendirmek amacıyla Ware tarafından geliştirilen bir bireysel değerlendirme aracıdır [12]. SF-36 yaşam kalitesi ölçeğinin Türkçe geçerlik ve güvenirliği Koçyiğit ve arkadaşları tarafından 1999 yılında çalışılmıştır [13]. SF-36 literatürde oldukça sık kullanılan yaşam kalitesi ölçeklerinden biridir. Hızlı bir şekilde doldurulması ve yaşam kalitesini olumlu, olumsuz her iki yönden de değerlendirebilmesi diğer yaşam kalitesi ölçeklerine göre SF-36'yı üstün kılar. Ölçek sekiz alt boyut içermektedir bunlar; fiziksel fonksiyon, fiziksel rol güçlüğü, emosyonel rol güçlüğü, vitalite, ruhsal sağlık, sosyal işlevsellik, ağrı, genel sağlık algısıdır. Ölçeğin dördüncü ve beşinci sorusu evet/hayır, diğer sorular likert tipi (3, 5 ve 6'lı) derecelendirme ile değerlendirilmektedir. SF-36'nın toplam puanı bulunmamakla birlikte her alt ölçeğe ayrı puanlama yapılarak elde edilen puanlarda düşük puan kötü sağlığı, puan artışı iyi sağlık algısını göstermektedir.

Araştırmaya başlamadan önce Atatürk Üniversitesi Tıp Fakültesi Klinik Araştırmalar Etik Kurulu'ndan 08.12.2017 tarihli ve 03 nolu karar ile onay alınmış olup araştırma etik kural ilkelerine bağlı olarak yürütülmüştür. 


\section{İstatistiksel analiz}

Elde edilen veriler SPSS 22,0 (SPSS, Inc., Chicago, IL) istatistik panel programı ile analiz edilmiştir. Tanımlayıcı istatistikler ortanca,minimummaksimum değer ve yüzde olarak sunulmuş, yaşam kalitesine etkili olabilecek sosyodemografik faktörlerin normal dağılıma uygunluğu Kolmogrov Smirnov testi ile değerlendirilmiştir. Normal dağılıma uymayan verilerin analizinde Mann Whitney-U testi kullanılmıştır.

\section{Bulgular}

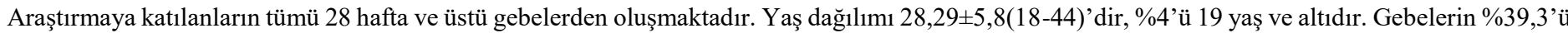
eşlerinin ise \%27,4'ü ilköğretim ve altı eğitim almıştır. Gebelerin \%77'sinin herhangi bir sosyal güvencesi vardır. Gebelerin eşlerinin meslek dağılımına bakıldığında serbest meslek $(\% 27)$, iş̧̧i $(\% 24,8)$ ve memurlar(\%20,4) en büyük grupları oluşturmaktadır. Araştırmaya katılan gebelerin evlilik y1l ortalamas $6.59 \pm 4.9$ olup \%29.6's 5 veya daha fazla kişiyle birlikte yaşamaktadır. İstenmeyen gebelik oranı \%21,7'dir.

Gebelerin \%24,8'inin ilk gebeliği, \%19'unun en az bir ve daha fazla düşü̆ü \%16,9'unun en az bir veya daha fazla kürtaj1 \%2,7'sinin ölü doğumu

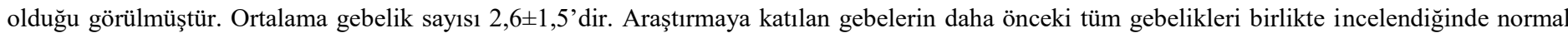
doğum $\% 44,2$, sezeryan ile doğum oranı ise $\% 27$ 'dir. Gebelikte destekleyici vitamin, demir takviyesi ve folik asit kullanmayan gebe oranı \%16,8, gebeliği esnasında herhangi bir rahatsızlık geçiren gebe oranı \%5,8, daha önceki gebeliklerinde herhangi önemli bir rahatsızlık geçirenler tüm gebelerrin \%8'ini oluşturmaktadır. Tansiyon, diyabet, hipotiroidi gibi kronik herhangi bir hastalığı olan gebeler araştırmanın \%15'ini oluşturmaktadır. Gebelerin \%79,6'sının gebelik esnasında 4 veya daha fazla şikayeti olmuştur (bulantı, kusma, baş ağrısı, bacak ağrısı, mide yanması, kabızlık, bel ağrısı, ayakta şişlik, hemoroid). Son bir ay içinde sigara içim oranı \%13,3, düzenli sigara içme oranı \%6,6'dır . Araştırmaya katılan gebelerin \% \%88,9'u hamileliğini öğrenince sevinmiş \%90,7'si yakınları tarafından desteklenmiştir.

Araştırmaya katılan gebelerin fiziksel fonksiyon alan puanı ortancası 55, fiziksel rol güçlüğü alan puanı ortancası 0 , emosyonel rol güçlüğü alan puanı ortancası 50 , vitalite alan puanı ortancası 35 , ruhsal sağlı alan puanı ortancası 68 ,sosyal işlevsellik alan puanı ortancası 75, ağrı alan puanı ortancası 40, genel sağlık algısı alan puanı ortancası 65 olarak hesaplanmıştır. Tablo 1'de araştırmaya katılan gebe kadınların bazı sosyo-demografik özelikleri ile yaşam kalitesi alan puanları karşılaştırılmıştır.

Fiziksel fonksiyon alan puanları; ilköğretim üzeri eğitim alanlarda, 5 ve daha fazla kişi bir arada yaşayanlarda, ilk gebeliği olanlarda, sigara içmeyenlerde daha yüksektir. Fiziksel rol güçlüğü sezeryan ile doğum yapanlarda ve sigara içenlerde emosyonel rol güçlügü alan puanı ise sadece sigara içmeyenlerde daha yüksektir. Vitalite alan puanları; ilköğretim üzeri eğitim alanlarda, düzenli geliri olanlarda, isteyerek gebe kalanlarda, ilk kez gebe kalanlarda daha iyidir. Ruhsal sağlık alan puanları; kendi ve eşi ilköğretim üzeri eğitim alanlarda düzenli geliri olup sosyal güvencesi olanlarda isteyerek gebe kalanlarda, sigara içmeyenlerde ve kronik hastalığı olmayanlarda daha yüksektir. Sosyal işlevsellik alan puanları; kendi ve eşi ilköğretim üzeri eğitim alanlarda düzenli geliri olup sosyal güvencesi olanlarda, isteyerek gebe kalanlarda, sigara içmeyenlerde ve ilk gebeliği olanlarda daha yüksektir. Ağrı alan puanları; ilköğretim üzeri eğitim alanlarda, düzenli geliri ve sosyal güvencesi olanlarda, ilk gebeliği olanlarda ve isteyerek gebe kalanlarda yüksektir. Genel sağlık algısı alan puanı; karşılaştırma yapılan tüm parametrelerde anlamlı fark bulunmamıştır.

\section{Tartıșma}

Çalışmamızın sonuçları, evreni temsil eden örnekleme ulaşıldığı için Erzurum il merkezindeki 3. Trimester gebelere genellenebilir. Ancak; kesitsel bir araştırma olan çalışmamız yaşam kalitesi ile sosyodemografik değişkenler arasındaki ilişkiyi belirtmekle birlikte nedensellik ilişkisini açıklamakta yetersiz kalmaktadır.

Araştırmamıza katılan gebelerin yaş ortalaması 28,2 idi. İzmir de yapılan çalışmada gebelerin yaş ortalaması 26,4 olarak bulunmuştur [14]. Sivas da yapılan başka bir çalışmada da benzer sonuçlar görülmektedir [15,16]. TNSA-2008 ve sonrasında anne olma yaşı 20-24 yaş grubundan 25-29 yaş grubuna yükselmiştir. TNSA 2013 ve bizim çalışmamızda da benzer sonuçlar benzerlik göstermektedir [17]. Araştırmaya katılan gebelerin yaşı ile SF-36 yaşam kalitesi ölçeği alanlarında aldıkları ortalama puanlar karşılaştırıldığında, istatistiksel olarak anlamlı ilişki saptanmadı (p > 0,05).Daha önce İstanbul da yapılan başka bir çalışmada da yaş ile yaşam kalitesi ile anlamlı ilişki saptanmamıştır [18].

Bu çalışmada gebelerin \%39,3'ü eşlerinin ise \%27,4'ü ilköğretim ve altı eğitim almışlardır. Edirne'de yapılan bir çalışmada ise bu oranlar gebelerde $\% 27,1$ 'i, eşlerinde $\% 19,8$ 'dir. Bizim çalışmamızda okuryazar olmayan gebe oranı $\% 6,6$, eşlerinde ise bu oran $\% 2,2$ 'dir.Edirnede yapılan çalışmada ise okur-yazar olmama durumu gebe kadınlarda \%1'dir. Eşlerinde okur-yazar olmayan yoktur [19]. Eğitimin yaşam kalitesinin birden fazla alanında pozitif yönde etkilediği bizim çalışmamızda ve diğer yaşam kalitesi çalışmasında görülmüştür [20]. Literatürde gebelerin sağlığını etkileyen önemli faktörlerden birinin de eğitim ve sosyo-ekonomik düzey olduğu gösterilmiştir. Eğitim düzeyi arttıkça gebelerin düzenli takiplere gittiği, kontrollerini yaptırdıkları görülmüştür. Kadınların eğitim düzeylerinin artmasının ve sosyoekonomik durumunun iyileşmesinin, gebelerin bu özel dönemini daha sağlıklı ve rahat geçirmeleri üzerine etkisi vardır [21-23].

Araştırmamızdaki gebelerin gebelik öncesi sağlık durumu incelendiğinde, grubun \%15'inin kronik bir hastalığının (astım, tiroid, hipertansiyon) olduğunu belirtmiștir. İstanbul da yapılan Şahin ve ark (2008) çalışmalarında \%16, İran'da yapılan başka bir çalışmada gebelerin \%12'sinde kronik bir hastalık (astım, tiroid) saptanmıştır. Sonuçlar gebelik öncesi sağlık durumu açısından çalışmamızla benzerlik göstermektedir [24-25]. Çalışmamızda kronik hastalığı olan gebelerin ruhsal sağlık alan puanlarının düşük olduğu saptanmıştır. Bu durum kadınların varolan kronik hastalıklarının gebeliğine etkileri, gebeliğin hastalıklarına etkileri ve kullanmakta oldukları ilaçlar nedeniyle endişe duymalarından kaynaklanıyor olabilir. Kronik hastalıkları 
olan kadınların gebelik öncesi hastalıklarının gebelik süresince seyri hakkında danışmalık almaları, gebe kadınların hastalıklarıyla ilgili klinklere başvurularının kolaylıkla yapılmasının sağlanması kronik hastalığı olan gebelerin ruhsal sağlığını olumlu etkileyeceği düşünülmektedir.

\section{Tablo 1.Bazı Sosyo-Demografik Özelliklere Göre Yaşam Kalitesi}

\begin{tabular}{|c|c|c|c|c|c|c|c|c|c|}
\hline Özellik & $\mathbf{N}$ & $\begin{array}{c}\text { Fiziksel } \\
\text { fonksiyon } \\
\text { Ortanca } \\
\end{array}$ & $\begin{array}{l}\text { Fiziksel rol } \\
\text { güçlüğüu }\end{array}$ & $\begin{array}{l}\text { Emosyonel } \\
\text { rol güçlüğü }\end{array}$ & Vitalite & $\begin{array}{l}\text { Ruhsal } \\
\text { sağlık }\end{array}$ & $\begin{array}{c}\text { Sosyal } \\
\text { işlevsellik }\end{array}$ & Ağrı & $\begin{array}{c}\text { Genel } \\
\text { sağlık } \\
\text { algısı } \\
\end{array}$ \\
\hline \multicolumn{10}{|l|}{ Yaş } \\
\hline 19 yaş altı & 9 & $85(55-100)$ & $50(0-50)$ & $50(50-50)$ & $40(25-75)$ & $56(32-100)$ & $40(25-75)$ & $67,5(22,5-100)$ & $65(50-70)$ \\
\hline 19 yaş üstü & 217 & $55(0-100)$ & $0(0-50)$ & $50(0-50)$ & $35(0-90)$ & $68(16-100)$ & $75(0-100)$ & $47,5(0-100)$ & $65(15-90)$ \\
\hline $\mathrm{p}^{*}$ & & 0,058 & 0,056 & 0,384 & 0,332 & 0,153 & 0,209 & 0,380 & 0,436 \\
\hline \multicolumn{10}{|l|}{ Eğitim } \\
\hline İlköğretim ve altı & 89 & $55(0-100)$ & $0(0-50)$ & $0(0-50)$ & $35(0-85)$ & $64(20-100)$ & $62,5(0-100)$ & $32,5(0-100)$ & $65(20-85)$ \\
\hline İlköğretim üzeri & 137 & $65(10-100)$ & $0(0-50)$ & $50(0-50)$ & $40(5-90)$ & $72(16-100)$ & $75(0-100)$ & $57,5(0-100)$ & $65(15-90)$ \\
\hline $\mathrm{p}^{*}$ & & 0,042 & 0,999 & 0,864 & 0,047 & 0,004 & 0,000 & 0,089 & 0,454 \\
\hline \multicolumn{10}{|l|}{ Eş eğitim düzeyi } \\
\hline İlköğretim ve altı & 62 & $55(25-100)$ & $0(0-50)$ & $50(0-50)$ & $35(0-80)$ & $64(20-100)$ & $50(0-100)$ & $22,5(0-100)$ & $60(20-85)$ \\
\hline İlköğretim üzeri & 164 & $57,5(0-100)$ & $0(0-50)$ & $50(0-50)$ & $40(5-90)$ & $72(16-100)$ & $75(0-100)$ & $575(0-100)$ & $65(15-90)$ \\
\hline $\mathrm{p}^{*}$ & & 0,455 & 0,862 & 0,453 & 0,106 & 0,031 & 0,000 & 0,012 & 0,108 \\
\hline \multicolumn{10}{|l|}{ Sosyal güvence } \\
\hline Yok & 52 & $65(25-100)$ & $12,5(0-50)$ & $50(0-50)$ & $35(0-85)$ & $66(20-100)$ & $62,5(0-100)$ & $22,5(0-100)$ & $65(20-85)$ \\
\hline Var & 174 & $55(0-100)$ & $0(0-50)$ & $50(0-50)$ & $40(5-90)$ & $7(16-100)$ & $75(0-100)$ & $57,5(10-100)$ & $65(15-90)$ \\
\hline $\mathrm{p}^{*}$ & & 0,860 & 0,153 & 0,063 & 0,208 & 0,034 & 0,000 & 0,003 & 0,135 \\
\hline \multicolumn{10}{|l|}{ Düzenli gelir } \\
\hline Memur & 46 & $55(10-100)$ & $37,5(0-50)$ & $50(0-50)$ & $52,5(5-85)$ & $80(32-100)$ & $81,25(25-100)$ & $62,5(10-100)$ & $65(25-85)$ \\
\hline Serbest meslek & 61 & $55(0-100)$ & $0(0-50)$ & $50(0-50)$ & $35(0-90)$ & $68(20-100)$ & $75(0-100)$ & $45(0-100)$ & $65(15-90)$ \\
\hline $\mathrm{p}^{*}$ & & 0,269 & 0,102 & 0,756 & 0,001 & $\mathbf{0 , 0 0 0}$ & 0,000 & 0,007 & 0,820 \\
\hline \multicolumn{10}{|l|}{ Birlikte yaşayan } \\
\hline 4 kişi ve daha az & 155 & $55(0-100)$ & $0(0-50)$ & $50(0-50)$ & $35(5-85)$ & $68(16-100)$ & $75(0-100)$ & $57,5(0-100)$ & $65(20-90)$ \\
\hline 5 kişi veya daha çok & 67 & $70(10-100)$ & $0(0-50)$ & $50(0-50)$ & $35(0-90)$ & $68(16-100)$ & $75(0-100)$ & $47,5(0-100)$ & $65(20-85)$ \\
\hline $\mathrm{p}^{*}$ & & 0,046 & 0,605 & 0,602 & 0,740 & 0,463 & 0,304 & 0,348 & 0,765 \\
\hline \multicolumn{10}{|l|}{ Gebeliği isteme } \\
\hline İsteyenler & 177 & $65(0-100)$ & $0(0-50)$ & $50(0-50)$ & $40(5-90)$ & $68(16-100)$ & $75(0-100)$ & $57,5(0-100)$ & $65(15-90)$ \\
\hline İstemeyenler & 49 & $55(10-100)$ & $0(0-50)$ & $50(0-50)$ & $30(0-80)$ & $60(20-100)$ & $62,5(0-100)$ & $22,5(0-100)$ & $65(20-85)$ \\
\hline $\mathrm{p}^{*}$ & & 0,164 & 0,130 & 0,717 & 0,004 & 0,034 & 0,005 & 0,000 & 0,290 \\
\hline \multicolumn{10}{|l|}{ Gebelik } \\
\hline İlk gebelik & 56 & $70(0-100)$ & $18,75(0-50)$ & $50(0-50)$ & $45(10-90)$ & $70(16-100)$ & $87,5(0-100)$ & $57,5(0-100)$ & $65(15-85)$ \\
\hline 2 ve üzeri gebelik & 170 & $55(10-100)$ & $0(0-50)$ & $50(0-50)$ & $35(0-85)$ & $68(16-100)$ & $75(0-100)$ & $45(0-100)$ & $65(20-90)$ \\
\hline $\mathrm{p}^{*}$ & & 0,001 & 0,099 & 0,920 & 0,002 & 0,098 & 0,008 & 0,014 & 0,936 \\
\hline \multicolumn{10}{|l|}{ Sigara } \\
\hline İçen & 30 & $55(0-85)$ & $0(0-50)$ & $50(0-50)$ & $5(0-70)$ & $56(20-84)$ & $62,5(0-100)$ & $22,5(0-100)$ & $60(20-80)$ \\
\hline İçmeyen & 196 & $55(10-100)$ & $0(0-50)$ & $50(0-50)$ & $35(5-90)$ & $68(16-100)$ & $75(0-100)$ & $57,5(0-100)$ & $65(15-90)$ \\
\hline $\mathrm{p}^{*}$ & & $\mathbf{0 , 0 3 1}$ & 0,045 & $\mathbf{0 , 0 3 7}$ & 0,247 & 0,001 & 0,001 & 0,053 & 0,108 \\
\hline \multicolumn{10}{|l|}{ Doğum şekli } \\
\hline Normal doğum & 100 & $55(10-100)$ & $0(0-50)$ & $50(0-50)$ & $35(5-85)$ & $68(16-100)$ & $62,5(0-100)$ & $33,75(0-100)$ & $65(20-90)$ \\
\hline Sezeryan & 53 & $65(50-100)$ & $37,5(0-50)$ & $50(0-50)$ & $35(10-85)$ & $72(20-100)$ & $75(12,5-100)$ & $45(0-100)$ & $65(20-85)$ \\
\hline p* & & 0,077 & 0,034 & 0,442 & 0,891 & 0,193 & 0,133 & 0,502 & 0,196 \\
\hline \multicolumn{10}{|l|}{$\begin{array}{r}\text { Kronik hastalık } \\
\text { varlığı }\end{array}$} \\
\hline Evet & 34 & $55(30-100)$ & $0(0-50)$ & $50(33,3-50)$ & $35(0-90)$ & $62(20-100)$ & $75(0-100)$ & $22,5(0-100)$ & $60(20-85)$ \\
\hline Hayır & 192 & $60(0-100)$ & $0(0-50)$ & $50(0-50)$ & $35(5-85)$ & $68(16-100)$ & $75(0-100)$ & $57,5(0-100)$ & $65(15-90)$ \\
\hline $\mathrm{p}^{*}$ & & 0,459 & 0,662 & 0,257 & 0,972 & 0,019 & 0,654 & 0,093 & 0,075 \\
\hline
\end{tabular}

*Mann Whitney-U testi

Araştırmamıza katılan gebelerin \%21,7'sinin istemeden gebe kaldığ belirtilmiştir. Manisa'da yapılan çalışmada gebelerin \%19,1'inin istemeden gebe kaldığını belirtmiştir [9]. Edirne il merkezinde gebeliğin istenmeyen bir gebelik olması oranı \%9,1'dir [19]. İstemeden gebe kalanlar ve düzenli geliri olmayan gebelerde yaşam kalitesinin vitalite, ruhsal sağlık, sosyal işlevsellik, ağrı alan puanlarında fark saptanmıştır. TNSA 2013 verilerine göre ülkemizdeki gebelerin \%12,5'i istemeden gebe kalmış, \%11,2'si ise gebeliği daha sonra planlamaktayken gebe kalmıştır. Çalışma örneklemindeki gebelerin \%30,5'inin ilk gebeliğidir. İstenmeden gebe kalma oranları göz önünde bulundurulduğunda aile planlaması yöntemleri eğitimi ve danışmanlığa olan erişim yaygınlaştırılmalıdır [9,17]. Gebelerin sigara alışkanlıkları incelendiğinde son bir ay içinde sigara içme oranı \%13,3; düzenli sigara kullanım oranı ise \%6,6 olduğu görülmektedir. Erzurum'da 1991-1992 yılları arasında yapılan başka bir çalışmada bu düzenli sigara içme oranı \%3'dür [26]. Edirne'de bir çalışmada son 1 ayda sigara kullanan gebelerin oranı \%14,4'ydi ve bunlardan \%6,2'si halen düzenli sigara kullanmaktaydı [19]. Marakoğlu (2003)'nun Sivas ta yaptığı çalışmasında ise gebelikte sigara içme sıklığı \%17 olarak bildirilmiştir [27]. Sigara içme oranı geçmiş yıllara göre artmış görünmektedir fakat Sivas ve Edirne'de yapılan çalışmalardan düşük bulunmuştur. Çalışmamızda sigara kullanımının yaşam kalitesi alt alanlarından fiziksel fonksiyon, fiziksel rol güçlüğ̈̈, emosyonel rol güçlüğü, ruhsal săglık ve sosyal işlevselliği olumsuz etkilediği saptanmıştır. Toplumun sigara kullanım oranlarıyla karşılaştırıldığında gebelerin sigara kullanımı düşük olmasına rağmen hem kadın sağlığına hem bebek sağlı̆̆ına hem de gebelerin yaşam kalitesine olan negatif etkileri birlikte düşünüldüğünde ulusal tütün kontrol programı dahilinde gebelerin tütün kullanımıyla mücadelesine ayrıca önem verilmelidir. 


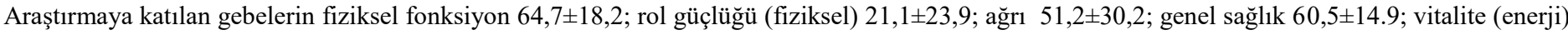

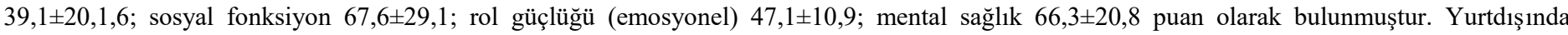
gebelerde yapılan bir çalışmada ise alan puan ortalamaları sırayla fiziksel fonksiyon $77,8 \pm 17.4$; fiziksel rol güçlüğü $70,2 \pm 24,3$; genel sağlık $69,1 \pm 16,9$;

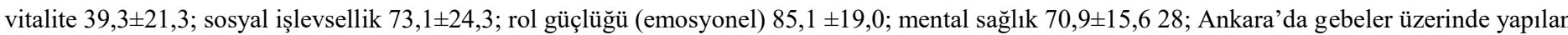

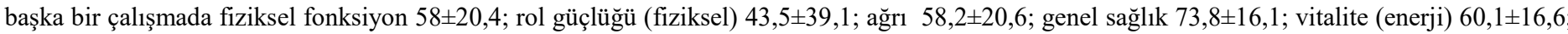

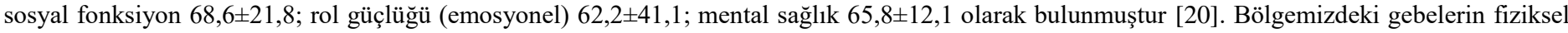
fonkisyon, fiziksel rol güçlüğü, genel sağlık ve emosyonel rol güçlüğü puanlarının daha düşük olduğu görülmektedir. Bu durum bölgeler arası sosyoekonomik gelişmişlik düzeyi farklarından kaynaklanıyor olabilir.

Ülkemizde sağlıklı kadınlarda yapılan çalışmada fiziksel fonksiyon $80.6 \pm 21,7$ rol güçlüğü(fiziksel) $82,9 \pm 28,6$ ağrı 81,0 $\pm 20,2$ genel sağlık $69,1 \pm 16,9$ vitalite $63,4 \pm 13,7$ sosyal işlevsellik $90,1 \pm 12,9$ rol güçlüğü(emosyonel) $89,0 \pm 22,5$ ruhsal sağlık 70,1 $\pm 11,4$ bulunmuştur [29]. Bizim araştırma sonuçlarımız sağlıklı normal kadınlarınkinden düşük ancak gebe kadınlarla yapılan araştırma sonuçları ile benzerdir. Yaşam kalitesiyle ilgili yapılan çok sayıda çalışmada sadece gebelik dönemi değil aynı zamanda postpartum dönemde de fiziksel ve fonksiyonel iyilik algısı gibi çeşitli ölçeklerin puanlarının düşük bulunduğu belirtilmiştir [30,31]. Ülkemizde yapılan birkaç çalışmada gebelerin sosyodemografik özellikleri ve yaşam kalitesi ilişkisi, gebelikte depresyon ve anksiyete düzeyleriyle yaşam kalitesi incelenmiştir [19,30]. Yapılan bir derlemede gebelikte yaşanan psikososyal değişikliklere çalışmalarda sıkça yer verildiği görülmüştür [32].

\section{Sonuç}

Çalışmamızda gebelerde eğitim düzeyinin yaşam kalitesinin pek çok alt boyutuna olumlu yansıdı̆̆ görülmüştür gebelerin eşlerinin de eğitimli olması, düzenli gelir ve sosyal güvence varlığı yaşam kalitesini önemli ölçüde etkilemiştir. Sağlıklı bir gebelik süreci geçirebilmek aynı zamanda isteyerek gebe kalan annelerde daha mümkün görünmektedir. Annelerin üreme sağlığı eğitim düzeyleri de arttırılmalıdır. Aile planlaması hizmetleri gereksinimi olan kişilere ulaştırılmalıdır.

Çıkar çatışması / Conflict of interest: Yok / none.

Destek / Funding: Yok / none.

\section{Kaynaklar}

1. Mendis S, Armstrong T, Bettcher D, Branca F, Lauer J, Mace C, et al. Global status report on noncommunicable diseases 2014. World Health Organization; 2015. http://www.who.int/nmh/publications/ncd-statusreport-2014/en/

2. World Health Organization. Constitution of the World Health Organization basic document. Geneva: World Health Organization; 1948.

3. Spitzer WO. State of science 1986: quality of life and functional status as target variables for research. Journal of chronic diseases. 1987;40(6):46571. doi: https://doi.org/10.1016/0021-9681(87)90002-6

4. Beşer N, Öz F. Kemoterapi alan lenfomalı hastaların hastane anksiyete depresyon düzeyi ve yaşam kalitesi. Cumhuriyet Univ Hemsire Yo Derg. 2003;7(1):47-56.

5. Ersin A. OKB tanısı olan çocuk ve ergenlerde belirti dağılımının ebeveynlerdeki Obsesif Kompülsif Belirti dağılımı ve ebeveyn tutumları ile olan ilişkisi: Ișik Üniversitesi; 2017.

6. Oskay ÜY, Coşkun A. Hastanede Yatak İstirahatindeki Yüksek Riskli Gebelerde Ortaya Çıkan Sorunların Giderilmesinde Verilen Kapsamlı Hemşirelik Bakımının Etkinliği. TAF Preventive Medicine Bulletin. 2012;11(2).

7. Taşkın L. Doğum ve Kadın Sağlı̆̆ Hemşireliği, Sistem Ofset, VI. Baskı, Ankara. 2005.

8. Babacan Gümüş A, Çevik N, Hataf Hyusni S, Biçen Ş, Keskin G, Tuna Malak A. Gebelikte benlik saygısı ve beden imajı ile ilişkili özellikler. Anatolian Journal of Clinical Investigation. 2011;5(1).

9. Altıparmak S. Gebelerde sosyo-demografik özellikler, öz bakım gücü ve yaşam kalitesi ilişkisi. TAF Preventive Medicine Bulletin. 2006;5(6).

10. Magee LA, Chandra K, Mazzotta P, Stewart D, Koren G, Guyatt GH. Development of a health-related quality of life instrument for nausea and vomiting of pregnancy. American journal of obstetrics and gynecology. 2002;186(5):S232-S8. doi: https://doi.org/10.1067/mob.2002.122604

11. Fiziksel DAGKA, Yakınmalar E. Afyon Kocatepe Üniversitesi Sağlık Bilimleri Enstitüsü Doğum ve Kadın Hastalıkları Hemşireliği. Yüksek Lisans Tezi, Afyon; 2006.

12. Ware Jr JE, Sherbourne CD. The MOS 36-item short-form health survey (SF-36): I. Conceptual framework and item selection. Medical care. 1992:473-83.

13. Kocyigit H. Reliability and validity of the Turkish version of short form-36 (SF-36): a study in a group of patients will rheumatic diseases. Turk J Drugs Ther. 1999;12:102-6.

14. Dülgerler Ş, Engin E, Ertem G. Gebelerin ruhsal belirti dağılımlarının incelenmesi. Ege Üniversitesi Hemşirelik Yüksek Okulu Dergisi. 2005;21(1):115-26.

15. Tarnowski M, Carlotto MS. Burnout Syndrome In Students Of Psychology. Temas Psicol. 2007;15(2):173-80. doi: http://dx.doi.org/10.6061/clinics/2012(06)05 
16. Nur N, Çetinkaya S, Bakır D, Demirel Y. Sivas il merkezindeki kadınlarda postnatal depresyon prevalansı ve risk faktörleri. Cumhuriyet Üniv Tıp Fak Derg. 2004;26(2):55-9.

17. Hacettepe Üniversitesi Nüfus Etütleri Enstitüsü (2014), “2013 Türkiye Nüfus ve Sağl1k Araştırmas1, Hacettepe Üniversitesi Nüfus Etütleri Enstitüsü, T.C. Kalkınma Bakanlığı ve TÜBİTAK,Ankara, Türkiye.

18. C.Arabacioglu. Gebelerde yaşam kalitesi ve eğitim gereksinimlerinin belirlenmesi. İstanbul Bilim Üniversitesi; 2012.

19. Kılıçarslan S. Edirne şehir merkezinde'ki son trimester gebelerin sosyodemografik özellikleri, yaşam kaliteleri, kaygı düzeyleri. Trakya Üniversitesi Tıp Fakültesi Aile Hekimliği Anabilim Dalı, Yayınlanmamış Uzmanlık Tezi, Edirne, 2008

20. Sönmezer E, Yosmaoğlu HB, Daşkapan A, Anaforoğlu B. Gebelerin anneliğe psikososyal uyumlarını etkileyen faktörler. Sağlık ve Toplum 2015; 25(2):46-54.

21. Şentürk V. Gebelik ve doğum sonrası dönemde sık görülen ruhsal bozukluklar. Kriz Dergisi 2008;16: 25-34.

22. Inandi T, Bugdayci R, Dundar P, Sumer H, Sasmaz T. Risk factors for depression in the first postnatal year. Soc Psychiatry Psychiatr Epidemiol 2005;40(9):725-30

23. Danaci AE, Dinç G, Deveci A, Şen FS, İçelli İ. Postnatal depression in Turkey: epidemiological and cultural aspects. Soc Psychiatry Psychiatr Epidemiol 2002;37(3):125-9.

24. Da Costa D, Dritsa M, Verreault N, Balaa C, Kudzman J, Khalifé S. Sleep problems and depressed mood negatively impact health-related quality of life during pregnancy. Arch Womens Ment Health 2010;13(3):249-57. DOI 10.1007/s00737-009-0104-3

25. Şahin N, Hüsniye D, Dişsiz M. Gebelerin doğuma ilişkin korkuları ve etkileyen faktörler. Zeynep Kamil Tip Bul 2009;40(2):57-62.

26. Alp H, Selimoğlu MA, Yaman S, Energin M, Altınkaynak S, Orbak Z. Gebelikte sigara kullanımının fetüsa etkileri. İst Çocuk Klin Derg 1995; 30:80-3.

27. Marakoğlu K, Sezer RE. Sivas’ta gebelikte sigara kullanımı. Cumhuriyet Üniv Tıp Fak Derg 2003;25(4):157-64.

28. Jomeen J, Martin CR. The factor structure of the SF-36 in early pregnancy. Journal of Psychosomatic Research 2005;59(3):131-8. doi: https://doi.org/10.1016/j.jpsychores.2005.02.018

29. Demiral Y, Ergor G, Unal B, Semin S, Akvardar Y, Kivircık B, et al. Normative data and discriminative properties of short form 36 (SF-36) in Turkish urban population. BMC Public Health 2006;6(1):247. doi: https://doi.org/10.1186/1471-2458-6-247

30. Gjerdingen DK, Froberg DG, Fontaine P. The effects of social support on women's health during pregnancy, labor and delivery, and the postpartum period. Family Medicine 1991;23(5):370-5. PMID:1884933

31. Mckee MD, Cunningham M, Jankowski KR, Zayas L. Health-related functional status in pregnancy: relationship to depression and social support in a multi-ethnic population. Obstetrics \& Gynecology 2001;97(6):988-93. doi: https://doi.org/10.1016/S0029-7844(01)01377-1

32. Özçelik G. Aydın İlinde Gebelikte Yaşanan Sağlık Sorunları ve Yaşam Kalitesi İle İlişkisi. Yüksek Lisans Tezi, Adnan Menderes Üniversitesi, Aydın; 2010. 